\title{
HESS Opinions: The complementary merits of top-down and bottom-up modelling philosophies in hydrology
}

\author{
Markus Hrachowitz ${ }^{1}$, Martyn Clark $^{2}$ \\ ${ }^{1}$ Faculty of Civil Engineering and Geosciences, Delft University of Technology, Stevinweg 1, 2628 CN Delft, Netherlands \\ $5 \quad{ }^{2}$ National Center for Atmospheric Research, Boulder CO, 80301, USA
}

Correspondence to: Markus Hrachowitz (m.hrachowitz@tudelft.nl)

\section{Supplementary Material}

\section{S1 - Example process complexity: Interception}

As an example consider which individual processes a description of vegetation interception at different hierarchal levels of detail may, amongst others, involve. At the level of individual tree branches, it can be split in into the individual respective interception capacities of a branch and its leaves. While the first is controlled by the mechanical water loading capacity of the branch, which in turn is a function of branch geometry, wind speed, wind direction and precipitation phase, the latter also depends on the phenology of the plant under consideration. Applying classical mechanics, information on material properties

15 and geometry of the branch-leave system together with time series of wind speed, wind direction, energy supply and precipitation then allows to compute time series of water storage in as well as drip and evaporation from the branch-leave system. At a higher hierarchal level, the level of the individual plant, the detailed, mechanistic description has to be extended to a three-dimensional cascade of individual, interacting branch-leave systems, each characterized by its own position and geometry and therefore affected by differences in wind exposure, direct precipitation input as well as throughfall from

20 systems above. For individual young plants with a few branch-leave systems, depending on how many of the material and geometric can be determined with some level of confidence, and how many may require some degree of lumping and simplifying conceptualizations, a mechanistic description may remain a feasible option. Yet, the overall interception at the level of a plant is the result of a distribution of different individual thresholds, i.e. interception capacities. With increasing complexity, the resulting non-linear system then becomes increasingly problematic to predict with a detailed, small-scale

25 description, due to uncertainties in boundary conditions, forcing and system states (e.g. Zehe et al., 2007). At the subsequent stand level, the detailed properties of different plants of the same species but also other species and the composition of plants at a given stand need to be known in addition if interception wants to be treated in a detailed way based on small scale physics. This is effectively not possible with current day observational and computational technology and may for a long time not be. In absence of the required detailed observations, observations at a higher hierarchal level and/or calibration are 
required to establish a meaningful process parameterization. Both dictate a lower degree of process detail and thus a higher degree of integration to limit the effects of equifinality. In a system that is set in the realm of organized complexity - too random, i.e. unobservable, to be treated in a deterministic way and too organized to be treated in an exclusively statistical way (Dooge, 1986) - zooming out then often results in the emergence of simple, generalizable functional relationships of the

5 process under examination (here: interception) with some system properties (here for example Leaf Area Index, e.g. Samaniego et al., 2010) at that scale.

\section{S2 - Example process complexity: Water holding capacity in the unsaturated root zone}

A similar line of arguments as for interception holds for the emergent patterns of hydrological connectivity often observed at hillslope and small catchment scale. This underlines that even hillslopes that can be characterized by considerable natural

10 heterogeneity exhibit relatively stable but simple, threshold-like functional relationships between water storage and runoff generation (e.g. Detty and McGuire, 2010; Penna et al., 2011; McMillan, 2012; McMillan et al., 2014). One of the most convincing emergent pattern observed so far, however, describes the water holding capacity in the unsaturated root zone $\left(S_{U, \max }\right)$, i.e. the volume of water storage accessible to roots for transpiration, effectively reflecting the water volume between field capacity and permanent wilting point. A traditional approach for a detailed representation of this system component,

15 used in both top-down and bottom-up models, is based on soil porosity and estimates of root depth. Yet, neither effective values of porosity and its depth distributions nor effective estimates of root-depths are typically available at the scale of the modelling unit. Rather, these values are derived from interpolated point or plot scale observations at some spatial, typically excessively coarse, resolution in specific environments. Although the root-zone is a complex system with considerable heterogeneity, a detailed representation of its water holding capacity in a model using for example a range of different soil

20 layers and average root depths of some plant samples is therefore likely to result in serious misrepresentations of the boundary conditions of the system. In contrast, when zooming out to the macroscale, there is considerable evidence that the integrated water holding capacity in the unsaturated root zone can be robustly estimated at a range of scales exclusively based on the observed water balance for that domain (e.g. Kleidon and Heimann, 1998; Gao et al., 2014; deBoer-Euser et al., 2016; Nijzink et al., 2016a) as a simple process of water supply vs. deficit that emerges from the small scale complexity in

25 the root-soil system. Making it conceptually independent of porosity and root-depth allows to understand the process of water storage purely from the perspective of its specific ecohydrological function at that scale: to satisfy plant water demand of the prevailing ecosystem. Not only offering a simpler and more robust way to estimate the plant available water holding capacity (deBoer-Euser et al., 2016), it is also causally more coherent: a given water volume is accessible because the climatic conditions forced the plant to efficiently develop its root system to provide sufficient continuous access to water

30 throughout dry periods, irrespective of soil characteristics, but not more than that to also ensure the allocation of sufficient resources for surface-growth, needed in competition with other plants. In other words, posing that plants of the same species "act" within the same limits of operation, the same plants in the same climate but on different soils (and thus different porosity) will need access to the same water volumes. They will therefore need to develop different root-systems to access 
this volume. As neither for individual plants nor for different compositions of plant communities and/or ecosystems detailed estimates of root-depths are available, the use of some average root-depth (obtained from literature or a few sample plants) will then not carry enough meaningful information on the actual water holding capacity, which is the hydrologically critical aspect of this system, but merely reflect the soil characteristics.

\section{S3 - Example: spatial complexity}

Many typical lumped top-down models, such as the 3-box HBV model, have originally been developed and adapted for application in cool, humid regions. In such environments, large parts of catchments do often exhibit only limited storage deficits and can remain hydrologically connected for much of the year. Although natural heterogeneities are in principle present in these systems, the fact that many thresholds, such as the interception capacity or the water holding capacity in the

10 unsaturated root zone, that control flow generation are exceeded for lengthy periods (i.e. connectivity!) results in more linear and spatially more homogenous response pattern than in more arid environments where the differences in connectivity are more pronounced due to the stronger effect of the relevant thresholds and their spatial distribution. This is not only true for heterogeneities introduced by geology, soil types and vegetation but also by heterogeneity in topographic features. This is underlined by the strong experimental evidence that different landscape elements, such as hillslopes and riparian zones (or

15 wetlands), often exhibit distinct response dynamics (e.g. Seibert et al., 2003; Freer et al., 2004; McGlynn et al., 2004).

As an illustrative example consider a catchment in such a cool, humid climate with little precipitation seasonality. The elevated precipitation volumes and short inter-storm durations together with limited energy supply for evaporation will result in interception and unsaturated root zone stores that are often filled close to their capacity, notwithstanding their potentially significant storage capacities (e.g. forest). As little additional water can be stored, the systems converges towards a linear

20 response, i.e. what is going in, goes out without significant storage changes and largely independent from spatially heterogeneous storage capacities across the entire catchment. Thus, in that example, any spatial heterogeneity of storage capacities, as for instance dictated by different land cover across the catchment, does not significantly influence the hydrological response and may therefore neither be meaningfully identified by the available data nor actually necessary to account for in a model. As the same applies for other processes, it can be argued that lumped top-down models, if rigorously

25 tested, may indeed be capable of meaningfully reproducing the observed hydrological response under these specific environmental conditions. However, the more arid the climate and the higher the seasonality of precipitation, the more pronounced the importance of the storage capacities and their spatial heterogeneity become: after a dry period, forested hillslopes with higher interception and unsaturated root-zone storage capacities than grasslands in the riparian zone will need more water to overcome the storage deficits. Thus riparian grasslands will, due to the lower storage deficit that needs to be

30 overcome, establish hydrological connectivity earlier than forests, which has, depending on the areal proportion of the two landscape elements within the catchment, considerable potential to influence the entire catchment response. A lumped formulation of the process will then indeed lead to a considerable misrepresentation of the hydrological system if a model 
customized for cool and humid conditions is applied under drier and warmer conditions, and further exacerbated by pronounced differences in topographic relief and/or land cover within the catchment.

Lumped models may thus allow suitable representations of the system response in some specific situations, but are likely to miss features of the hydrological response introduced by natural heterogeneity in many other environments. Yet, a wide

5 range of studies has in the past shown the potential of top-down models with (semi-)distributed (1) moisture accounting schemes and/or (2) model formulations to alleviate this problem.

On the one hand, if precipitation data from several rain gauges or even in a fully distributed way from remote sensing products (e.g. TRMM) are available, a model can considerably benefit from their direct use. The advantage of doing that is that at least some of the spatial structure in precipitation is more likely to be preserved than when applying some kind of

10 interpolated and lumped catchment average areal precipitation, which almost inevitably implies that the observed extremes are averaged out. Given the non-linear character of the system, controlled by storage thresholds and their spatial heterogeneity, using some sort of average value will result in a misrepresentation of the system dynamics.

Adopting a (semi-)distributed moisture accounting strategy, a top-down model can then be operated using parallel independent components for the zones in a catchment with different precipitation inputs (e.g. grid cells of remote sensing

15 product or Thiessen polygons), aggregating their outputs proportionally to the respective areas they cover within a catchment. Note, that this does not necessarily require a higher number of model parameters as compared to a lumped formulation: the model can be operated with the same parameter values in all precipitation zones, depending on the available information on the system (Ajami et al., 2004; Das et al., 2008; Kling and Gupta, 2009). In addition, the combined flow retarding low pass filter effects of interception and unsaturated storages in a catchment can considerably buffer and thus

20 reduce the effect of heterogeneity in the groundwater. This implies that (semi-)distributed soil moisture accounting is most effective for model components that represent near-surface processes and may in many cases be not be necessary for deeper processes, such as groundwater (Oudin et al., 2004; Fenicia et al., 2008; Euser et al., 2015). Oudin et al. (2004) further emphasized that the value of (semi-)distributed moisture accounting depends on both, the spatio-temporal scale of a storm and the spatial scale of a modelled catchment.

25 On the other hand, there is a long history of (semi-)distributed applications of top-down models that account for functional differences in a catchment introduced by heterogeneity in the boundary conditions. This can be done by discretizing the modelling domain on basis of regular grids (e.g. Samaniego et al., 2010; Kumar et al., 2013), sub-catchments (e.g. Boyle et al., 2001; Winsemius et al., 2008), functionally similar hydrological response units (HRU; Flügel, 1995) or as a combination of the above (e.g. Nijzink et al., 2016b). Previously HRUs were defined by soils and geology (e.g. Uhlenbrook et al., 2004;

30 Schmocker-Fackel et al., 2007), land cover (e.g. Uhlenbrook et al., 2010) or topography (e.g. Beven and Kirkby, 1979; Knudsen et al., 1986; Seibert et al., 2003; Savenije, 2010; Gharari et al., 2014) or a combination thereof (e.g. Winter, 2001; Wolock et al., 2004; Zehe et al., 2014). Although any spatial resolution of the discretization is theoretically possible, limits to the resolution are in reality dictated by the available information/data to meaningfully constrain the model. The difference 
to using spatially distributed input data is that here the individual parallel model units are characterized by different parameters, thereby inflating the feasible parameter space and the problems arising from the associated equifinality.

\section{S4 - Example: climate effects on importance of processes}

As an example, interception may not significantly influence the hydrological functioning in energy limited cool and humid

5 environments, as the interception storage may be filled close to capacity for much of the year due to frequent precipitation inputs and limited evaporation losses. Originally developed for use in such environments, this process is therefore switched off in the HBV model by using an informed prior, i.e. by fixing the parameter defining the interception capacity to a value of zero, and therefore effectively omitted in the original model. Yet, the relative importance of individual processes in different environments is varying as a function of climate and terrestrial boundary conditions, such as soils or land cover. Thus, while

10 the interception process is switched off in a model developed in cool, humid regions, it may become more important in more water limited warm, arid regions with a higher energy supply, where precipitation supplies less input and higher evaporation rates drain the interception storage faster, which, on average, provides available storage in the interception component. In other words, water storage in the interception reservoir exceeds its storage threshold less often and more irregularly. Needless to stress that similar thought processes apply for parts of the hydrological system other than interception as well.

15 other modelling strategy has to offer in order to strengthen their very own models.

\section{Supplementary Material References}

Ajami, N. K., Gupta, H., Wagener, T., \& Sorooshian, S. (2004). Calibration of a semi-distributed hydrologic model for streamflow estimation along a river system. Journal of Hydrology, 298(1), 112-135.

Beven, K. J., \& Kirkby, M. J. (1979). A physically based, variable contributing area model of basin hydrology/Un modèle à base physique de zone d'appel variable de l'hydrologie du bassin versant. Hydrological Sciences Journal, 24(1), 43-69.

Das, T., Bárdossy, A., Zehe, E., \& He, Y. (2008). Comparison of conceptual model performance using different representations of spatial variability. Journal of Hydrology, 356(1), 106-118.

de Boer-Euser, T., McMillan, H. K., Hrachowitz, M., Winsemius, H. C., \& Savenije, H. H. (2016). Influence of soil and climate on root zone storage capacity. Water Resources Research, 52, 2009-2024.

25 Boyle, D. P., Gupta, H. V., Sorooshian, S., Koren, V., Zhang, Z., \& Smith, M. (2001). Toward improved streamflow forecasts: Value of semidistributed modeling. Water Resources Research, 37(11), 2749-2759.

Detty, J. M., \& McGuire, K. J. (2010). Topographic controls on shallow groundwater dynamics: implications of hydrologic connectivity between hillslopes and riparian zones in a till mantled catchment. Hydrological Processes, 24(16), 2222-2236.

Dooge, J. C. (1986). Looking for hydrologic laws. Water Resources Research, 22(9S).

30 Euser, T., Hrachowitz, M., Winsemius, H. C., \& Savenije, H. H. (2015). The effect of forcing and landscape distribution on performance and consistency of model structures. Hydrological Processes, 29(17), 3727-3743. 
Fenicia, F., Savenije, H. H., Matgen, P., \& Pfister, L. (2008). Understanding catchment behavior through stepwise model concept improvement. Water Resources Research, 44(1).

Flügel, W. A. (1995). Delineating hydrological response units by geographical information system analyses for regional hydrological modelling using PRMS/MMS in the drainage basin of the River Bröl, Germany. Hydrological Processes, 9(34), 423-436.

Freer, J. E., McMillan, H., McDonnell, J. J., \& Beven, K. J. (2004). Constraining dynamic TOPMODEL responses for imprecise water table information using fuzzy rule based performance measures. Journal of Hydrology, 291(3), 254-277.

Gao, H., Hrachowitz, M., Schymanski, S. J., Fenicia, F., Sriwongsitanon, N., \& Savenije, H. H. G. (2014). Climate controls how ecosystems size the root zone storage capacity at catchment scale. Geophysical Research Letters, 41(22), 7916-7923.

10 Gharari, S., Hrachowitz, M., Fenecia, F., Gao, H., \& Savenije, H. H. G. (2014). Using expert knowledge to increase realism in environmental system models can dramatically reduce the need for calibration. Hydrology and Earth System Sciences, $18,4839-4859$.

Kleidon, A., \& Heimann, M. (1998). A method of determining rooting depth from a terrestrial biosphere model and its impacts on the global water and carbon cycle. Global Change Biology, 4(3), 275-286.

15 Kling, H., \& Gupta, H. (2009). On the development of regionalization relationships for lumped watershed models: The impact of ignoring sub-basin scale variability. Journal of Hydrology, 373(3), 337-351.

Knudsen, J., Thomsen, A., \& Refsgaard, J. C. (1986). WATBAL. Hydrology Research, 17(4-5), 347-362.

Kumar, R., Samaniego, L., \& Attinger, S. (2013). Implications of distributed hydrologic model parameterization on water fluxes at multiple scales and locations. Water Resources Research, 49(1), 360-379.

20 McGlynn, B. L., McDonnell, J. J., Seibert, J., \& Kendall, C. (2004). Scale effects on headwater catchment runoff timing, flow sources, and groundwater- streamflow relations. Water Resources Research, 40(7).

McMillan, H. K. (2012). Effect of spatial variability and seasonality in soil moisture on drainage thresholds and fluxes in a conceptual hydrological model. Hydrological Processes, 26(18), 2838-2844.

McMillan, H., Gueguen, M., Grimon, E., Woods, R., Clark, M., \& Rupp, D. E. (2014). Spatial variability of hydrological processes and model structure diagnostics in a $50 \mathrm{~km} 2$ catchment. Hydrological Processes, 28(18), 4896-4913.

Nijzink, R., Hutton, C., Pechlivanidis, I., Capell, R., Arheimer, B., Freer, J., Han, D., Wagener, T., McGuire, K., Savenije, H., \& Hrachowitz, M. (2016a). The evolution of root-zone moisture capacities after deforestation: a step towards hydrological predictions under change?. Hydrology and Earth System Sciences, 20(12), 4775-4799.

Nijzink, R. C., Samaniego, L., Mai, J., Kumar, R., Thober, S., Zink, M., Schäfer, D., Savenije, H. H. G., \& Hrachowitz, M.

30 (2016b). The importance of topography-controlled sub-grid process heterogeneity and semi-quantitative prior constraints in distributed hydrological models. Hydrology and Earth System Sciences, 20(3), 1151-1176.

Oudin, L., Andréassian, V., Perrin, C., \& Anctil, F. (2004). Locating the sources of low- pass behavior within rainfallrunoff models. Water Resources Research, 40(11). 
Penna, D., Tromp-van Meerveld, H. J., Gobbi, A., Borga, M., \& Dalla Fontana, G. (2011). The influence of soil moisture on threshold runoff generation processes in an alpine headwater catchment. Hydrology and Earth System Sciences, 15(3), 689-702.

Samaniego, L., Kumar, R., \& Attinger, S. (2010). Multiscale parameter regionalization of a grid- based hydrologic model at 5 the mesoscale. Water Resources Research, 46(5).

Savenije, H. H. G. (2010). HESS Opinions" Topography driven conceptual modelling (FLEX-Topo)". Hydrology and Earth System Sciences, 14(12), 2681-2692.

Schmocker-Fackel, P., Naef, F., \& Scherrer, S. (2007). Identifying runoff processes on the plot and catchment scale. Hydrology and Earth System Sciences, 11(2), 891-906.

10 Seibert, J., Rodhe, A., \& Bishop, K. (2003). Simulating interactions between saturated and unsaturated storage in a conceptual runoff model. Hydrological Processes, 17(2), 379-390.

Uhlenbrook, S., Roser, S., \& Tilch, N. (2004). Hydrological process representation at the meso-scale: the potential of a distributed, conceptual catchment model. Journal of Hydrology, 291(3), 278-296.

Uhlenbrook, S., Mohamed, Y., \& Gragne, A. S. (2010). Analyzing catchment behavior through catchment modeling in the Gilgel Abay, upper Blue Nile River basin, Ethiopia. Hydrology and Earth System Sciences, 14(10), 2153-2165.

Winsemius, H. C., H. H. G. Savenije, and W. G. M. Bastiaanssen (2008). "Constraining model parameters on remotely sensed evaporation: justification for distribution in ungauged basins?." Hydrol. Earth Syst. Sci., 12, 1403-1413.

Winter, T. C. (2001). The concept of hydrologic landscapes. Journal of the American Water Resources Association, 37(2), 335-349.

20 Wolock, D. M., Winter, T. C., \& McMahon, G. (2004). Delineation and evaluation of hydrologic-landscape regions in the United States using geographic information system tools and multivariate statistical analyses. Environmental Management, 34(1), S71-S88.

Zehe, E., Elsenbeer, H., Lindenmaier, F., Schulz, K., \& Blöschl, G. (2007). Patterns of predictability in hydrological threshold systems. Water Resources Research, 43(7).

25 Zehe, E., Ehret, U., Pfister, L., Blume, T., Schröder, B., Westhoff, M., Jackisch, C., Schymanski, S. J., Weiler, M., Schulz, K., Allroggen, N., Tronicke, J., van Schaik, L., Dietrich, P., Scherer, U., Eccard, J., Wulfmeyer, V., \& Kleidon, A. (2014). HESS Opinions: From response units to functional units: a thermodynamic reinterpretation of the HRU concept to link spatial organization and functioning of intermediate scale catchments. Hydrology and Earth System Sciences, 18(11), $4635-4655$. 